\title{
Evaluation of patient satisfaction of an outpatient gastroscopy service in an Asian tertiary care hospital
}

Najib Azmi, Wah-Kheong Chan ${ }^{*}$ and Khean-Lee Goh

\begin{abstract}
Background: There are limited published studies on patient satisfaction towards endoscopy from Asian countries. Different methods of evaluation of patient satisfaction may yield different results and there is currently no study to compare results of on-site versus phone-back interviews.

Method: On-site followed by phone-back interviews were carried out on consecutive patients attending the outpatient gastroscopy service of University of Malaya Medical Centre between July 2010 and January 2011 using the modified Group Health Association of America-9 (mGHAA-9) questionnaire. The question on technical skill of endoscopist was replaced with a question on patient comfort during endoscopy.

Results: Seven hundred patients were interviewed. Waiting times for appointment and on gastroscopy day, and discomfort during procedure accounted for over $90 \%$ of unfavorable responses. Favorable response diminished to undesirable level when waiting times for appointment and on gastroscopy day exceeded 1 month and 1 hour, respectively. Satisfaction scores were higher for waiting time for appointment but lower for personal manner of nurses/staff and explanation given during phone-back interview. There was no significant difference in satisfaction scores for other questions, including overall rating between the two methods.

Conclusion: Waiting times and discomfort during procedure were main causes for patient dissatisfaction. Phoneback interview may result in different scores for some items compared with on-site interview and should be taken into account when comparing results using the different methods.
\end{abstract}

Keywords: Gastroscopy, Patient satisfaction, Patient comfort, Waiting time

\section{Background}

Patient satisfaction is considered a measure of a highquality endoscopy [1], and many endoscopy units administer patient satisfaction surveys for quality-control purposes [2]. Deficiencies in an endoscopy unit can be identified through such studies and these can then be analyzed and solutions can be made to improve the overall quality of endoscopy. Patient satisfaction also affects health care outcomes. Patients who are dissatisfied are likely to be non-compliant [3], transfer care to other centres [4] and engage in litigation issues [5]. From the business point of view, satisfaction scores can

\footnotetext{
* Correspondence: wahkheong2003@hotmail.com

Division of Gastroenterology, Department of Medicine, Faculty of Medicine, University of Malaya, 50603 Kuala Lumpur, Malaysia
}

be used for marketing purposes if they are sufficiently impressive [6].

The Endoscopy Suite in University of Malaya Medical Centre caters to 3000 - 3200 gastroscopies per year. In the year 2010, over 2000 outpatient gastroscopies were performed and the number is increasing. Despite this figure, no studies have been done to assess patient satisfaction. Therefore we decided to perform a survey to assess patient satisfaction of our outpatient gastroscopy service and to identify areas of dissatisfaction for improvement. Moreover, there are limited published studies on patient satisfaction towards endoscopy from Asian countries.

Many studies on patient satisfaction were carried out immediately after the procedure [7-9]. Sedation given during the procedure may affect patient satisfaction

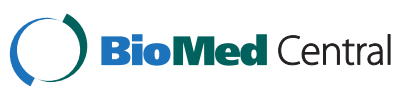


score and this raises the question on whether answering a questionnaire immediately after the procedure may yield different satisfaction scores compared to administering the questionnaire at a later date. In a study by Lin et al [10], on-site survey resulted in higher satisfaction scores compared to mail back survey. Besides the possible influence of sedation, it was hypothesized that patients may feel disinclined to give low satisfaction scores in the presence of endoscopy unit staff. Another study by Harewood et al [11] reported that survey methods that involved more personal interaction such as onsite surveys and phone interviews tend to generate higher response rates than less personal methods such as mail back surveys and electronic mail surveys. To the best of our knowledge, there is till date no study comparing on-site interview and phone interview in terms of success rate and patient satisfaction score of endoscopy services. Thus, the secondary aim of our study is to compare the results of immediate on-site interview and delayed phone interview in these aspects.

\section{Outpatient gastroscopy Service in University of Malaya Medical Centre}

Our center practices an open-access outpatient gastroscopy service receiving patients from primary care clinics, other specialist clinics and those discharged from inpatient wards in addition to patients from the gastroenterology clinic. Gastroscopy appointments are given on a first-come-first-serve basis. When a patient is deemed to require an earlier gastroscopy appointment, the doctor-in-charge would negotiate the patient's appointment to an earlier date. Appointment time on gastroscopy day is staggered fifteen minutes per patient per room to reduce waiting time. A support staff will register patients and a staff nurse will help patients prepare for the procedure. Explanation about the procedure is given and consent is obtained by the endoscopist before the procedure. Two rooms run simultaneously for gastroscopy during each session. Blood pressure, pulse rate, respiratory rate and oxygen saturation is recorded before the procedure. Lignocaine $1 \%$ pharyngeal spray is administered to all patients. All patients receive intravenous Midazolam $2.5 \mathrm{mg}$ to $5 \mathrm{mg}$ as sedation prior to the procedure unless they have requested not to be given sedation or it is deemed unsafe by the endoscopist. The dosage is given at the discretion of the endoscopist based on subjective assessment. Gastroscopy is performed by various grades of endoscopist including consultants, specialists, and trainees under supervision. Different types of gastroscopes with varying diameters are used. During the procedure, pulse rate and oxygen saturation is monitored continuously. Following the procedure, patients rest in the recovery area till they regain full consciousness before they are seen by the endoscopist-in-charge at the discharge counter who would explain the gastroscopy findings to them before they go home.

\section{Methods}

This is a cross sectional study of consecutive patients attending the outpatient gastroscopy service in University of Malaya Medical Centre between July 2010 and January 2011. Written informed consent was obtained from all patients and the study was approved by the ethical committee of this institution.

\section{During gastroscopy}

The observer assessment for alertness/sedation scale (OAASS) [12] was used in this study as an objective measurement of the level of patient sedation just before the procedure began (OAASS scale: $1-5$ ). The scale is sensitive to the amount of midazolam administered [12] and correlates well with the American Society of Anesthesiology (ASA) level of sedation [13] (ASA level of sedation: mild, moderate, deep correlates with OAASS scale: $5,2-4,1$, respectively).

\section{On-site interview}

The interview was carried out using an investigatoradministered questionnaire (see below) in an isolated room in the Endoscopy Suite immediately after the patients have received explanation from and were discharged by their endoscopist. Additional information such as name, telephone number, age, sex, race, education level, previous gastroscopy, waiting time for appointment, waiting time on gastroscopy day, indication for gastroscopy, duration of the procedure and sedation given were recorded. Waiting time for appointment refers to the duration from the day the gastroscopy was planned to the day that it was performed and was categorized as $<1$ week, $1-2$ weeks, $2-4$ weeks and $>4$ weeks. Waiting time on gastroscopy day refers to the duration from the time of registration on the day of the procedure to the time the procedure was performed and was categorized as $<1 / 2$ hour, $1 / 2-1$ hour, $1-2$ hours and $>2$ hours.

\section{The questionnaire and assessment of patient response}

We used the modified Group Health Association of America-9 (mGHAA-9) questionnaire but replaced the question on technical skill of endoscopist with a question on patient comfort level during endoscopy as proposed by Rio et al [14]. The questionnaire consists of the following: Q1 - Length of time spent waiting for the appointment, Q2 - Length of time spent waiting at the Endoscopy Suite for the procedure, Q3 - Personal manner of the physician who performed the procedure, Q4 Personal manner of the nurses and other support staff, Q5 - Adequacy of explanation of what was done for 


\begin{tabular}{|c|c|}
\hline \multicolumn{2}{|l|}{ Gender, n (\%) } \\
\hline Male & $326(47 \%)$ \\
\hline Female & $374(53 \%)$ \\
\hline \multicolumn{2}{|l|}{ Race, n (\%) } \\
\hline Malay & $203(29 \%)$ \\
\hline Chinese & $290(41 \%)$ \\
\hline Indian & $199(28 \%)$ \\
\hline Others & $8(1 \%)$ \\
\hline \multicolumn{2}{|l|}{ Education level, n (\%) } \\
\hline None & $106(15 \%)$ \\
\hline Primary & $115(16 \%)$ \\
\hline Secondary & $299(43 \%)$ \\
\hline Tertiary & $180(26 \%)$ \\
\hline \multicolumn{2}{|l|}{ History of previous gastroscopy, n (\%) } \\
\hline Yes & $299(43 \%)$ \\
\hline No & 401 (57\%) \\
\hline \multicolumn{2}{|l|}{ Indication, n (\%) } \\
\hline Suspected peptic ulcer disease & $454(65 \%)$ \\
\hline Suspected malignancy & $100(14 \%)$ \\
\hline Gastroesophageal reflux disease & $73(10 \%)$ \\
\hline Variceal surveillance & $21(3 \%)$ \\
\hline Anemia for investigation & $47(7 \%)$ \\
\hline Procedural & $5(1 \%)$ \\
\hline \multicolumn{2}{|l|}{ Duration of gastroscopy, n (\%) } \\
\hline$\leq 10$ minutes & $407(58.1 \%)$ \\
\hline$>10$ minutes & $293(41.9 \%)$ \\
\hline \multicolumn{2}{|l|}{ Sedation, n (\%) } \\
\hline Yes & $641(92 \%)$ \\
\hline No & $59(8 \%)$ \\
\hline
\end{tabular}

Amount of midazolam given, $\mathrm{n}(\%)$

$$
\begin{aligned}
& \leq 2.5 \mathrm{mg} \\
& >2.5 \mathrm{mg}
\end{aligned}
$$

Level of sedation according to OAASS, $\mathrm{n}(\%)$

$\begin{array}{lc}1 & 2(0.3 \%) \\ 2 & 60(8.6 \%) \\ 3 & 426(60.9 \%) \\ 4 & 110(15.7 \%) \\ 5 & 102(14.6 \%)\end{array}$

The two patients who were deeply sedated (OAASS $=1$ ) were grouped into the same group as patients who were moderately sedated (OAASS $=2-4$ ) due to the small number and for ease of statistical analysis. OAASS = observer assessment for alertness/sedation scale.

you, Q6 - Comfort level during the procedure, Q7 Overall rating of the visit, Q8 - Would you have the procedure done again by this physician? Q9 - Would you have the procedure done again at this facility? The original ordinal five-value Likert scale (excellent, very good, good, fair, and poor) was used. Patient response for each of the questions Q1 to Q7 was dichotomized to favorable (excellent, very good, good) and unfavorable (fair, poor). The percentages of favorable and unfavorable responses for each of the questions were calculated. A problem rate was also estimated by dividing the sum of unfavorable responses with the sum of questions asked and multiplying by 100 . A Pareto chart was used to illustrate the contribution of each of the questions to the overall unfavorable responses. Finally, the percentages of favorable and unfavorable responses were estimated across the categories of waiting time for appointment and waiting time on gastroscopy day.

\section{Telephone interview}

All patients were contacted by phone within a month from the day of the procedure for a second interview using the same questionnaire. Patients who did not respond after 3 random calls were excluded. The interval of the phone-back interview from the day of the procedure was recorded. A different interviewer not involved in the on-site interview and who was blinded to the response of the on-site interview administered the questionnaire through phone interview. Patients who were unwilling to participate or did not answer all the questions were excluded. We gave a score to patient response for each of the questions Q1 to Q7 (poor $=1$, fair $=2$, good $=3$, very good $=4$, excellent $=5$ ) to compare patient response during on-site interview and during phone-back interview.

\section{Statistical analysis}

Data were analyzed using a standard statistical software program (SPSS 16.0). Continuous variables were expressed as means with standard deviations. Categorical variables were analyzed using chi-square test. Variables with $\mathrm{p}$-value $<0.20$ on univariate analysis were entered into multivariate analysis using logistic regression. Mean and median scores for each of the questions Q1 to Q7 as well as the mean and median total scores for on-site interview and for phone-back interview were calculated. The median scores for each of the questions for the two groups were compared using Wilcoxon Signed Rank Sum test. Significance was defined as p-value $<0.05$.

\section{Results}

A total of 735 patients came for outpatient gastroscopy during the study period. Seven hundred patients were interviewed. Twenty eight patients declined to participate while seven others were excluded because of considerable language barrier. Mean age of the study population was $54.9 \pm 15$ years, with minimum age of 15 years old and maximum age of 91 years old. Patient 
characteristics and procedure-related information are shown in Table 1.

\section{Patient response for Q1 to Q6}

The questions which had the most unfavorable responses were that on waiting time for appointment followed by waiting time on gastroscopy day and comfort level during procedure. High favorable response rates were seen for the other 3 questions (Figure 1).

\section{Problem rate and pareto analysis}

The problem rate was $17.4 \%$ (732 unfavorable responses out of total 4200 questions asked). Waiting time for appointment, waiting time on gastroscopy day and discomfort during procedure constituted over $90 \%$ of these unfavorable responses (Figure 2).

\section{Waiting time for appointment}

Nearly two thirds of the patients had to wait for more than 4 weeks for their appointment $(10 \%$ waited $\leq 1$ week, $9 \%$ waited $1-2$ weeks, $19 \%$ waited $2-4$ weeks, $62 \%$ waited $>4$ weeks). Favorable response diminished to undesirable level (from $79.4 \%$ to $41.8 \%$ ) when waiting time for appointment exceeded 4 weeks (Figure 3). Patients with shorter waiting time for appointment ( $\mathrm{p}$ $<0.001$ ), those over 55 years old ( $\mathrm{p}$-value $=0.022$ ) and those who never had a gastroscopy before $(\mathrm{p}<0.001)$ were more likely to give favorable response towards waiting time for appointment on univariate analysis. Gender, ethnicity and education level did not affect patient satisfaction towards waiting time for appointment (data not shown). Only shorter waiting time for appointment $(\mathrm{p}<0.001)$ and history of previous gastroscopy $(\mathrm{p}=0.001)$ were independent predictors of

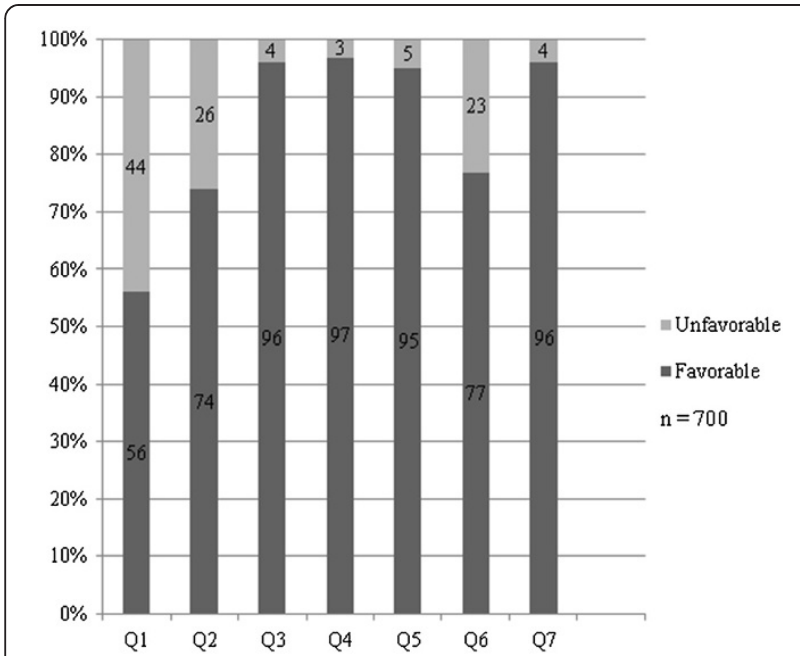

Figure 1 Patient responses for questions Q1 to Q7. favorable response towards waiting time for appointment on multivariate analysis.

\section{Waiting time on gastroscopy day}

More than half of the patients had to wait for over 1 hour for their turn on gastroscopy day ( $12 \%$ waited $\leq 1 / 2$ hour, $34 \%$ waited $1 / 2-1$ hour, $43 \%$ waited $1-2$ hours, $11 \%$ waited $>2$ hours). Favorable response diminished to undesirable level (from 90.5\% to 67.8\%) when waiting time on gastroscopy day exceeded 1 hour (Figure 4). Age, gender, ethnicity, education level and history of previous gastroscopy did not affect patient satisfaction towards waiting time on gastroscopy day (data not shown). Only shorter waiting time $(\mathrm{p}<0.001)$ was found to be an independent predictor of favorable response towards waiting time on gastroscopy day on multivariate analysis.

\section{Discomfort during procedure}

Twenty three percent of patients gave unfavorable response for comfort during procedure. Younger patients (55 years old or less) $(p=0.002)$, females $(p=0.007)$, and patients not given sedation $(\mathrm{p}<0.001)$, given lower dosage of sedation $(\mathrm{p}<0.001)$ or failed to achieve adequate (moderate) sedation according to MOAASS $(\mathrm{p}<$ 0.001 ) were more likely to give unfavorable response towards comfort level during procedure. However, only female gender and failure to achieve adequate (moderate)

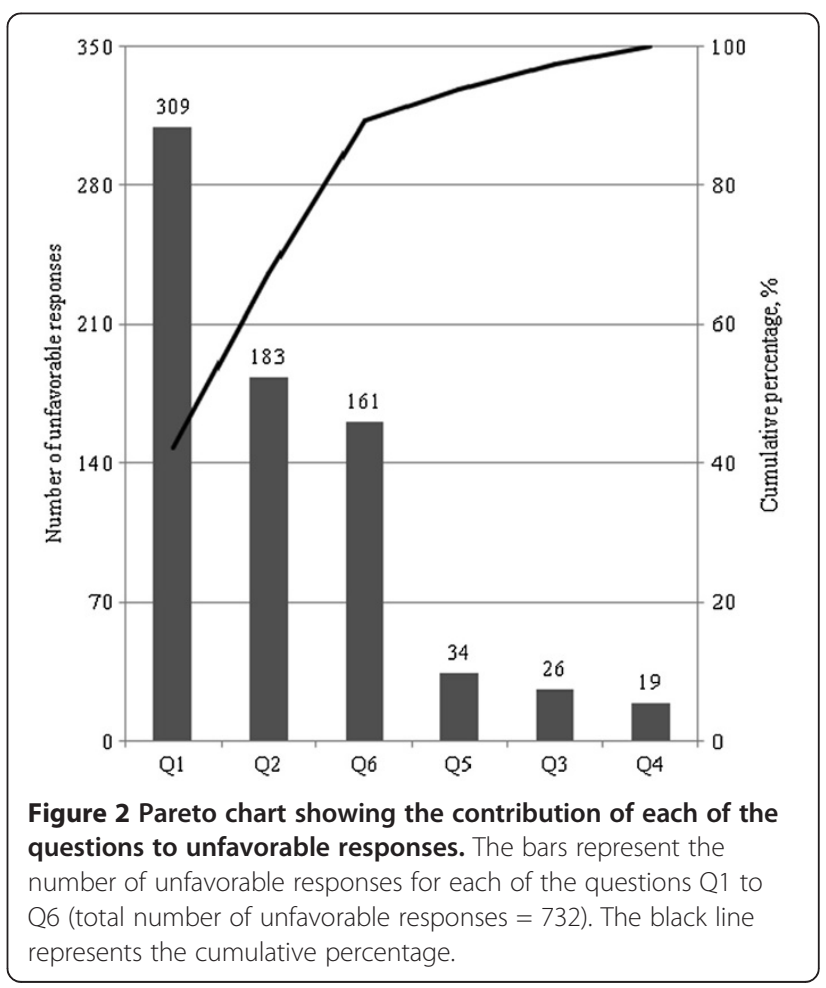




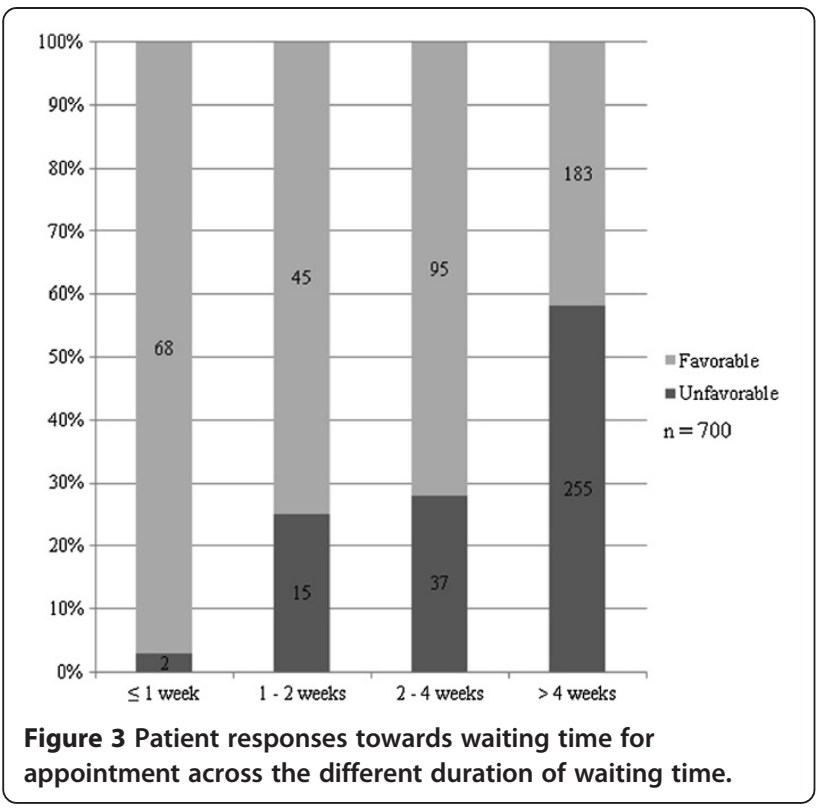

sedation according to MOAASS were independent predictors of unfavorable response towards comfort level during procedure.

\section{Factors associated with favorable overall rating}

Ninety six percent of patients gave favorable response for overall rating. The following factors were associated with favorable overall rating on univariate analysis: use of sedation, achieving at least moderate level of sedation during procedure, favorable response to each of the six questions and waiting time gastroscopy day of one hour or less. Factors that were associated with favorable

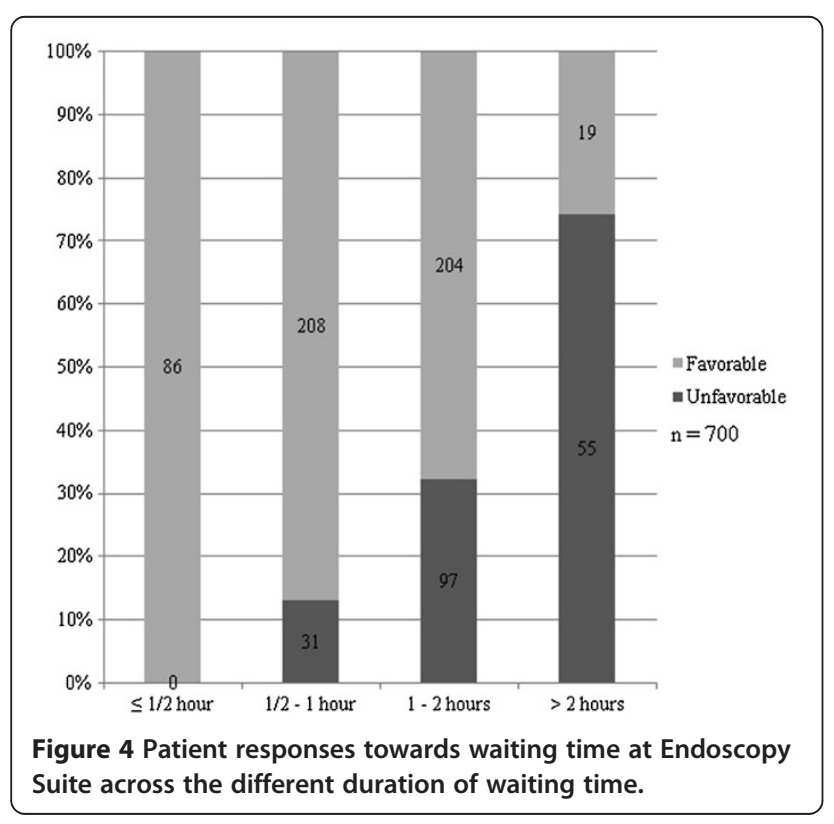

overall rating on multivariate analysis are favorable responses to the following: waiting time for appointment, waiting time on gastroscopy day, personal manner of endoscopist, explanation given by endoscopist and comfort level during procedure (Table 2). Majority of patients would return to the same physician (96.3\%) and to the same centre $(99.7 \%)$ should they need to undergo the same procedure in the future. Patients who gave favorable overall rating were more likely to do so (data not shown).

\section{On-site survey and phone-back survey}

Mean interval of phone-back interview from procedure day was $12 \pm 6$ days. Of the 700 patients interviewed onsite, only 511 patients $(73 \%)$ completed the phone-back interview. The reasons for unsuccessful phone-back interview are shown in Figure 5. Patients aged more than 55 years old were more likely to complete the phone-back interview than patients less than 55 years old $(\mathrm{p}=0.033)$. Response to phone-back interview was not influenced by gender or race (data not shown).

The mean total score for Q1 to Q7 was $23.0 \pm 3.8$ for on-site interview and $22.9 \pm 3.5$ for phone-back interview. The median total score was 22 and was the same for both groups. Because the Likert scale that we used only had 5 possible values, we often ended with identical median score for the on-site and phone-back groups. The mean scores for waiting time for appointment, waiting time on gastroscopy day, personal manner of endoscopist and comfort during procedure were higher while the mean scores for personal manner of nurse/staff and explanation given were lower in the phone-back group. The differences were statistically significant for waiting time for appointment, personal manner of nurse/staff and explanation given (Table 3). The mean scores were same for overall rating for both groups.

\section{Discussion}

Evaluation of patient satisfaction and addressing areas of dissatisfaction is an important aspect of healthcare services and is a measure of quality of service provided. This process has been found to be useful in improving standards of endoscopy centers including performance of endoscopists, and possibly the reputation of endoscopy centers in the long run [2]. Patient satisfaction also affects perception of the population at large towards endoscopic services and can have significant impact on patient willingness to undergo endoscopic procedures regardless of whether the patient has had endoscopy before.

Different questionnaires have been used to assess patient satisfaction towards gastrointestinal endoscopy $[10,14,15]$. The American Society of Gastrointestinal Endoscopists (ASGE) recommended the use of the 
Table 2 Univariate and multivariate analysis of patient demographics, procedure-related information and response to questions Q1 to Q6 with patient overall

rating

\begin{tabular}{|c|c|c|c|c|c|c|c|c|}
\hline \multirow[t]{2}{*}{ Factors } & \multicolumn{2}{|l|}{$\begin{array}{l}\text { Overall } \\
\text { Satisfaction }\end{array}$} & \multirow[t]{2}{*}{$\begin{array}{l}\text { Unadjusted } \\
\text { OR }\end{array}$} & \multirow[t]{2}{*}{$95 \% \mathrm{Cl}$} & \multirow[t]{2}{*}{$\begin{array}{l}p \\
\text { value }\end{array}$} & \multirow[t]{2}{*}{$\begin{array}{l}\text { Adjusted } \\
\text { OR }\end{array}$} & \multirow[t]{2}{*}{$95 \% \mathrm{Cl}$} & \multirow[t]{2}{*}{$\begin{array}{l}\mathrm{p} \\
\text { value }\end{array}$} \\
\hline & Favorable & Unfavorable & & & & & & \\
\hline \multicolumn{9}{|l|}{ Age } \\
\hline$\leq 55$ & $312(96.3 \%)$ & $12(3.7 \%)$ & 0.81 & $0.38,1.73$ & 0.589 & - & - & - \\
\hline$>55$ & $359(95.5 \%)$ & $17(4.5 \%)$ & & & & & & \\
\hline \multicolumn{9}{|l|}{ Sex } \\
\hline Male & $314(96.3 \%)$ & $12(3.7 \%)$ & 0.80 & $>0.38,1.71$ & 0.568 & - & - & - \\
\hline Female & $357(95.5 \%)$ & $17(4.5 \%)$ & & & & & & \\
\hline \multicolumn{9}{|l|}{ Ethnicity } \\
\hline Malay & $199(98 \%)$ & $4(2 \%)$ & & & & & & \\
\hline Chinese & $276(95.2 \%)$ & $14(4 . \%)$ & 0.69 & $0.43,1.10$ & 0.120 & 0.61 & $0.31,1.19$ & 0.149 \\
\hline Indian & $188(94.5 \%)$ & $11(5.5 \%)$ & & & & & & \\
\hline Others & $8(100 \%)$ & $0(0 \%)$ & & & & & & \\
\hline \multicolumn{9}{|l|}{ Education Level } \\
\hline Primary & $110(95.7 \%)$ & $5(4.3 \%)$ & & & & & & \\
\hline Secondary & $287(96 \%)$ & $12(4.0 \%)$ & 0.98 & $0.66,1.46$ & 0.915 & - & - & - \\
\hline Tertiary & $173(96.1 \%)$ & $7(3.9 \%)$ & & & & & & \\
\hline None & $101(95.3 \%)$ & $5(4.7 \%)$ & & & & & & \\
\hline \multicolumn{9}{|c|}{ Previous gastroscopy } \\
\hline Yes & $286(95.7 \%)$ & $13(4.3 \%)$ & 1.09 & $0.52,2.31$ & 0.814 & - & - & - \\
\hline No & 385 (96\%) & $16(4 \%)$ & & & & & & \\
\hline \multicolumn{9}{|c|}{ Duration of gastroscopy } \\
\hline$\leq 10$ minutes & $392(96.3 \%)$ & $15(3.7 \%)$ & 0.76 & $0.36,1.61$ & 0.474 & - & - & - \\
\hline$>10$ minutes & $279(95.2 \%)$ & $14(4.8 \%)$ & & & & - & - & - \\
\hline \multicolumn{9}{|l|}{ Sedation } \\
\hline Yes & $618(96.4 \%)$ & $23(3.6 \%)$ & 0.33 & $0.13,0.84$ & 0.015 & 0.51 & $0.12,2.19$ & 0.368 \\
\hline No & $53(89.8 \%)$ & $6(10.2 \%)$ & & & & & & \\
\hline \multicolumn{9}{|l|}{ Midazolam dose } \\
\hline$\leq 2.5 \mathrm{mg}$ & $228(95.8 \%)$ & $10(4.2 \%)$ & 1.32 & $0.57,3.05$ & 0.521 & - & - & - \\
\hline$>2.5 \mathrm{mg}$ & 390 (96.8\%) & 13 (3.2\%) & & & & & & \\
\hline
\end{tabular}


Table 2 Univariate and multivariate analysis of patient demographics, procedure-related information and response to questions Q1 to Q6 with patient overall rating (Continued)

\begin{tabular}{|c|c|c|c|c|c|c|c|c|}
\hline \multicolumn{9}{|l|}{ OAASS } \\
\hline 2 - 4 (moderately sedated) & $584(97.7 \%)$ & $14(2.3 \%)$ & 0.14 & $0.07,0.30$ & $<0.001$ & 0.65 & $0.18,2.32$ & 0.508 \\
\hline 5 (minimally sedated) & $87(85.3 \%)$ & $15(14.7 \%)$ & & & & & & \\
\hline \multicolumn{9}{|c|}{ Response for waiting time for appointment } \\
\hline Favorable & $386(98.7 \%)$ & $5(1.3 \%)$ & 6.50 & $2.32,19.67$ & $<0.001$ & 3.73 & $1.18,11.9$ & 0.026 \\
\hline Unfavorable & 285 (92.2\%) & $24(7.8 \%)$ & & & & & & \\
\hline \multicolumn{9}{|l|}{ Waiting time for appointment } \\
\hline$\leq 4$ weeks & $251(95.8 \%)$ & $11(4.2 \%)$ & 1.02 & $0.48,2.20$ & 0.954 & - & - & - \\
\hline$>4$ weeks & $420(95.9 \%)$ & $18(4.1 \%)$ & & & & & & \\
\hline \multicolumn{9}{|c|}{ Response for waiting time at Endoscopy Suite } \\
\hline Favorable & $510(98.6 \%)$ & $7(1.4 \%)$ & 9.96 & $3.95,26.14$ & $<0.001$ & 6.23 & $1.98,19.63$ & 0.002 \\
\hline Unfavorable & $161(88 \%)$ & $22(12 \%)$ & & & & & & \\
\hline \multicolumn{9}{|l|}{ Waiting time at Endoscopy Suite } \\
\hline$\leq 1$ hour & $320(98.5 \%)$ & $5(1.5 \%)$ & 0.23 & $0.09,0.61$ & 0.001 & 0.63 & $0.18,2.18$ & 0.465 \\
\hline$>1$ hour & $351(93.6 \%)$ & $24(6.4 \%)$ & & & & & & \\
\hline \multicolumn{9}{|c|}{ Response to personal manner of endoscopist } \\
\hline Favorable & $657(97.5 \%)$ & $17(2.5 \%)$ & 33.13 & $12.2,90.69$ & $<0.001$ & 15.15 & $3.73,61.58$ & 0.000 \\
\hline Unfavorable & $14(53.8 \%)$ & $12(46.2 \%)$ & & & & & & \\
\hline \multicolumn{9}{|c|}{ Response to personal manner of staff/nurses } \\
\hline Favorable & $660(96.9 \%)$ & $21(3.1 \%)$ & 22.86 & $7.46,69.81$ & $<0.001$ & 1.29 & $0.21,7.82$ & 0.784 \\
\hline Unfavorable & $11(57.9 \%)$ & $8(42.1 \%)$ & & & & & & \\
\hline \multicolumn{9}{|l|}{ Response to explanation given } \\
\hline Favorable & $646(97 \%)$ & $20(3 \%)$ & 11.36 & $4.39,30.38$ & $<0.001$ & 7.40 & $2.01,27.32$ & 0.003 \\
\hline Unfavorable & $25(73.5 \%)$ & $9(26.5 \%)$ & & & & & & \\
\hline \multicolumn{9}{|c|}{ Response to comfort level during endoscopy } \\
\hline Favorable & $532(98.7 \%)$ & $7(1.3 \%)$ & 12.03 & $4.76,31.66$ & $<0.001$ & 5.41 & $1.73,16.90$ & 0.004 \\
\hline Unfavorable & 139 (86.3\%) & $22(13.7 \%)$ & & & & & & \\
\hline
\end{tabular}

OAASS = observer assessment for alertness/sedation scale. 


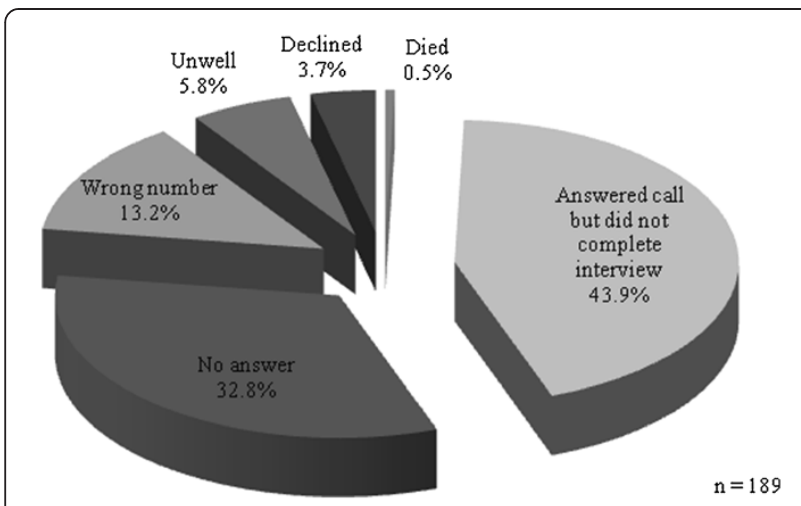

Figure 5 Reasons for unsuccessful phone-back interview.

mGHAA-9 questionnaire to measure patient satisfaction [15]. However, mGHAA-9 does not contain a question on patient comfort which has been found to be an important factor influencing patient satisfaction [16]. It was also noted that patients had difficulty answering the question on technical skills of endoscopist found in mGHAA-9 [14]. We anticipated a similar problem with our patients and have substituted this question with one on patient comfort.

As different health care system may vary in term of aspects that patients consider being important [17], areas of dissatisfaction unique to local patient population should be identified and analyzed and corrective measures instituted for improvement accordingly. Five independent factors affecting overall rating were identified in our population: waiting time for appointment, waiting time on gastroscopy day, personal manner of physician, adequacy of explanation and discomfort during procedure. Of these, waiting times and discomfort during procedure ranked the highest in terms of unfavorable responses.

Increasing number of patients scheduled for gastroscopy and limited resources have resulted in long appointment waiting times in our center while prolonged waiting on the day of gastroscopy may be the result of combination of factors including over-scheduling of cases for each session. Nearly half of our patients were dissatisfied with waiting time for gastroscopy appointment while close to one quarter were unhappy with their waiting on gastroscopy day. As dissatisfaction towards appointment waiting time could have resulted in a proportion of patients transferring to another outpatient gastroscopy service, our figure could be an underestimation of the true proportion of patients who were dissatisfied in this aspect. Waiting times for endoscopy appointment and on endoscopy day are problems not restricted to our center but appear to be major causes of unfavorable responses in other centers as well [18-21]. In this aspect, it is vital that increasing patient load is matched by increasing allocation of resources to maintain a service that meets the expectations of not only patients but also of healthcare providers.

Discomfort during procedure was recognized as the main cause of patient dissatisfaction in some studies $[22,23]$. Despite using proven measures to minimize discomfort during gastroscopy, including pharyngeal anesthesia and conscious sedation [7-9,24], nearly a

Table 3 Comparison of mean and median scores for questions Q1 to Q7 for on-site interview and phone interview

\begin{tabular}{|c|c|c|c|c|c|c|c|}
\hline \multirow[t]{2}{*}{ Questions } & \multicolumn{3}{|l|}{ Phone-back } & \multicolumn{3}{|l|}{ On-site } & \multirow{2}{*}{$\begin{array}{l}p \\
\text { value }\end{array}$} \\
\hline & Mean (SD) & $\begin{array}{c}\text { Median } \\
(25 Q-75 Q)\end{array}$ & $\begin{array}{c}\text { Low Score } \\
\text { Details }\end{array}$ & Mean (SD) & $\begin{array}{l}\text { Median } \\
(25 Q-75 Q)\end{array}$ & $\begin{array}{c}\text { Low Score } \\
\text { Details }\end{array}$ & \\
\hline \multirow[t]{2}{*}{ Waiting time for appointment } & $2.89(0.69)$ & $3(2-3)$ & $2(141), 1(0)$ & $2.78(0.92)$ & $3(2-3)$ & 2 (199), 1 (18) & 0.001 \\
\hline & & & $<2(141$ or $27.6 \%)$ & & & $<2(217$ or $42.5 \%)$ & \\
\hline \multirow[t]{2}{*}{ Waiting time at Endoscopy Suite } & $3.07(0.71)$ & $3(3-3)$ & $2(97), 1(0)$ & $3.06(0.85)$ & $3(3-4)$ & $2(99), 1(14)$ & 0.868 \\
\hline & & & $<2(97$ or $19 \%)$ & & & $<2(113$ or $22.1 \%)$ & \\
\hline \multirow[t]{2}{*}{ Personal manner of endoscopist } & $3.60(0.73)$ & $4(3-4)$ & $2(13), 1(2)$ & $3.57(0.74)$ & $4(3-4)$ & $2(19), 1(1)$ & 0.329 \\
\hline & & & $<2(15$ or $2.9 \%)$ & & & $<2(20$ or $3.9 \%)$ & \\
\hline \multirow[t]{2}{*}{ Personal manner of nurses/staff } & $3.32(0.71)$ & $3(3-4)$ & $2(39), 1$ (4) & $3.53(0.68)$ & $3(3-4)$ & $2(13), 1(0)$ & $<0.001$ \\
\hline & & & $<2(43$ or $8.4 \%)$ & & & $<2(13$ or $2.5 \%)$ & \\
\hline \multirow[t]{2}{*}{ Explanation given } & $3.36(0.74)$ & $3(3-4)$ & $2(36), 1(4)$ & $3.43(0.73)$ & $3(3-4)$ & $2(21), 1(1)$ & 0.035 \\
\hline & & & $<2(40$ or $7.8 \%)$ & & & $<2(22$ or $4.3 \%)$ & \\
\hline \multirow[t]{2}{*}{ Comfort level during procedure } & $3.22(0.85)$ & $3(3-4)$ & $2(54), 1(19)$ & $3.00(0.98)$ & $3(3-4)$ & $2(91), 1(22)$ & 0.288 \\
\hline & & & $<2(73$ or $14.3 \%)$ & & & $<2(113$ or $22.1 \%)$ & \\
\hline \multirow[t]{2}{*}{ Overall satisfaction } & $3.47(0.72)$ & $3(3-4)$ & $2(24), 1(2)$ & $3.47(0.70)$ & $3(3-4)$ & $2(16), 1(0)$ & 0.371 \\
\hline & & & $<2(26$ or $5.1 \%)$ & & & $<2(16$ or 3.1$)$ & \\
\hline
\end{tabular}


quarter of our patients were not satisfied. We found that patients who were only minimally sedated were more likely to give unfavorable response for comfort during procedure (data not shown). In this aspect, routine use of OAASS as an objective measure of adequate (moderate) sedation prior to commencing the procedure may be of benefit. Besides sedation, other factors such as the diameter of the endoscope [25] and level of experience of the endoscopist [23] may affect the level of comfort during the procedure. However, our study was not designed to look into these factors.

Besides waiting times and discomfort during procedure, other factors have yielded unfavorable responses from our patients. However, utilizing the principle of "vital few and trivial many" [26], we identified that waiting times and discomfort during procedure constituted to nearly $90 \%$ of the problems faced by our patients. By focusing on improvement in these aspects, there is great likelihood of substantially reducing the problem rate among patients attending our outpatient gastroscopy service. Based on our analysis, aiming for gastroscopy appointment waiting time of within 1 month and waiting time on gastroscopy day of within 1 hour will result in an improved rate of favorable response to nearly $80 \%$ and over $90 \%$, respectively. However, as this is a singlecenter study, this result may not be generalizable to other populations. Nevertheless, by using a similar approach, other centers may be able to gauge the waiting times that are acceptable for their patient population.

Previous studies have shown that survey collection method may impact on subject responses. Phone-back methods are generally associated with more favorable responses compared to mail-back methods [27-30] although some studies did not find any difference between the two methods $[11,31,32]$. Among patients who underwent endoscopy, satisfaction scores were better when surveys were completed on-site compared with when they were mailed back [10,22]. Interesting terms such as "social desirability response" bias (patients giving better responses than they feel because they feel it is more acceptable) and "ingratiating response" bias (patients giving better responses than they feel because they wish to ingratiate themselves with their providers) have been used for the phenomenon where satisfaction scores were better when obtained through more personal and earlier communications with patients [6]. Success rates are also generally better with on-site and phone-back methods compared with mail-back methods $[11,27,28,32]$. To our best knowledge, no studies have been conducted to compare on-site interview versus phone-back interview in evaluation of patient satisfaction of endoscopy services.

We found that satisfaction scores were better for waiting time for appointment but lower for personal manner of nurses/staff and for adequacy of explanation during phone-back interview compared with on-site interview. We hypothesize that dissatisfaction towards waiting time for appointment naturally diminished over time after the procedure helped in reassuring patients when there was nothing wrong or facilitated effective treatment following accurate diagnosis of the underlying condition. On the other hand, patients may have been more reluctant to give a low score for personal manner of nurses/staff and for adequacy of explanation during the on-site interview while still within the vicinity of the Endoscopy Suite. There was no significant difference in satisfaction scores for other questions, including overall rating between the two methods although there was a trend towards better scores during phone-back interview. This factor should be considered when comparing individual items of the questionnaire between centers or between two time-points in the same center if different methods (i.e. on-site vs. phone-back) were used. However, overall rating and some of the items may still be comparable. Caution should also be exercised when interviewing patients through phone-back when they have missed their on-site interview in patient satisfaction studies as some of the results may not be comparable when obtained using the two different methods. We would prefer on-site interview when conducting satisfaction survey due to its better success rate and because it is arguably easier and less costly to administer compared with phone-back interview.

Our center practices an open-access outpatient gastroscopy service receiving patients from primary care clinics, other specialist clinics and those discharged from in-patient wards in addition to patients from the gastroenterology clinic. Hence data from this study is generalizable to populations scheduled for gastroscopy at large. Despite our efforts, this study has several limitations. Firstly, we conducted the interview on the same group of patients and the response to the second interview may be biased by that of the first interview. Our findings should be confirmed with randomized study of two distinct groups of patients i.e. one for on site interview while the other for phone interview. Secondly, while the questionnaire used has obvious face validity, it has not been formally validated for our local population. There is currently no formally validated satisfaction survey questionnaire for endoscopy for our local population.

\section{Conclusion}

We found waiting times and discomfort during procedure to be the main causes for patient dissatisfaction towards the outpatient gastroscopy service of an Asian tertiary hospital. Measures to reduce waiting times for gastroscopy appointment and on gastroscopy day to less than 1 month and 1 hour, respectively may 
improve patient satisfaction substantially. Phone-back interview may result in different patient satisfaction scores compared with on-site interview. This should be taken into account when comparing results obtained using these two different methods. On site interview may be preferred as it gives a better success rate and is arguably easier and less costly to administer.

\section{Competing interests}

The authors declare that they have no competing interests.

\section{Authors' contributions}

NA contributed through data collection, data entry, data analysis and interpretation, and drafting of the article. WKC contributed through conception and design, data analysis and interpretation, and critical revision of the article for important intellectual content. KLG contributed through conception and design, critical revision of the article for important intellectual content, and final approval of the article. All authors read and approved the final manuscript.

Received: 22 March 2012 Accepted: 19 July 2012

Published: 28 July 2012

\section{References}

1. Faigel DO, Pike IM, Baron TH, et al: Quality indicators for gastrointestinal endoscopic procedures: an introduction. Gastrointest Endosc 2006, 63:S3-S9.

2. Larsen IK, Grotmol T, Bretthauer M, et al: Continuous evaluation of patient satisfaction in endoscopy centres. Scand J Gastroenterol 2002, 37:850-855

3. Davis MS: Variation in patients' compliance with doctors' orders: medical practice and doctor-patient interaction. Psychiatry Med 1971, 2:31-54.

4. Kasteler J, Kane RL, Olsen DM, et al: Issues underlying prevalence of "doctor-shopping" behavior. J Health Soc Behav 1976, 17:329-339.

5. Vaccarino JM: Malpractice Theproblem in perspective. JAMA 1977, 238:861-863.

6. Lin OS: Less stick, more carrot: measuring and improving patient satisfaction with endoscopic procedures. Gastrointest Endosc 2009, 69:892-895

7. Campo R, Brullet E, Montserrat A, et al: Efficacy of low and standard midazolam doses for gastroscopy. A randomized, double-blind study. Eur J Gastroenterol Hepatol 2000, 12:187-190.

8. Froehlich F, Schwizer W, Thorens J, et al: Conscious sedation for gastroscopy: patient tolerance and cardiorespiratory parameters. Gastroenterology 1995, 108:697-704

9. Trevisani L, Sartori S, Gaudenzi P, et al: Upper gastrointestinal endoscopy: are preparatory interventions or conscious sedation effective? A randomized trial. World J Gastroenterol 2004, 10:3313-3317.

10. Lin OS, Schembre DB, Ayub K, et al: Patient satisfaction scores for endoscopic procedures: impact of a survey-collection method. Gastrointest Endosc 2007, 65:775-781.

11. Harewood GC, Yacavone RF, Locke GR 3rd, et al: Prospective comparison of endoscopy patient satisfaction surveys: e-mail versus standard mail versus telephone. Am J Gastroenterol 2001, 96:3312-3317.

12. Chernik DA, Gillings $D$, Laine $H$, et al: Validity and reliability of the Observer's Assessment of Alertness/Sedation Scale: study with intravenous midazolam. J Clin Psychopharmacol 1990, 10:244-251.

13. Gross JB, Bailey PL, Connis RT, et al: Practice guidelines for sedation and analgesia by non-anesthesiologists. Anesthesiology 2002, 96:1004-1017.

14. SanchezdelRio A, Alarcon Fernandez O, Baudet JS, et al: Reliability of the Spanish version of a brief questionnaire on patient satisfaction with gastrointestinal endoscopy. Rev Esp Enferm Dig 2005, 97:554-561.

15. Johanson JF, Schmitt CM, Deas TM Jr, et al: Quality and outcomes assessment in Gastrointestinal Endoscopy. Gastrointest Endosc 2000, 52:827-830.

16. Yacavone RF, Locke GR 3rd, Gostout CJ, et al: Factors influencing patient satisfaction with Gl endoscopy. Gastrointest Endosc 2001, 53:703-710.

17. Groenewegen PP, Kerssens $\mathrm{JJ}$, Sixma HJ, et al: What is important in evaluating health care quality? An international comparison of user views. BMC Health Serv Res 2005, 5:16.
18. Del Rio AS, Baudet JS, Fernandez OA, et al: Evaluation of patient satisfaction in gastrointestinal endoscopy. Eur I Gastroenterol Hepatol 2007, 19:896-900.

19. Rasool S, Ahmed S, Siddiqui S, et al: Evaluation of quality and patient satisfaction during endoscopic procedure: a cross sectional study from south Asian country. J Pak Med Assoc 2010, 60:990-995.

20. Trujillo-Benavides OE, Altamirano-Garcia AA, Baltazar-Montufar P: et al [Level of satisfaction from patients who undergone an endoscopic procedure and related factors.]. Rev Gastroenterol Mex 2010, 75:374-379.

21. Sanchez Del Rio A, Campo R, Llach J, et al: [Patient satisfaction in gastrointestinal endoscopy: results of a multicenter study]. Gastroenterol Hepatol 2008, 31:566-571.

22. Ko HH, Zhang H, Telford JJ, et al: Factors influencing patient satisfaction when undergoing endoscopic procedures. Gastrointest Endosc 2009, 69:883-891. quiz 91 e1.

23. Seip B, Huppertz-Hauss G, Sauar J, et al: Patients' satisfaction: an important factor in quality control of gastroscopies. Scand J Gastroenterol 2008, 43:1004-1011.

24. Mulcahy HE, Greaves RR, Ballinger A, et al: A double-blind randomized trial of low-dose versus high-dose topical anaesthesia in unsedated upper gastrointestinal endoscopy. Aliment Pharmacol Ther 1996, 10:975-979.

25. Horiuchi A, Nakayama Y: Unsedated ultrathin EGD by using a 5.2-mmdiameter videoscope: evaluation of acceptability and diagnostic accuracy. Gastrointest Endosc 2006, 64:868-873.

26. JM J: The quality improvement process. In: Juran JM GA, ed. Juran's Quality Handbook. 5th edition. New York: McGraw-Hil; 1999.

27. Burroughs TE, Waterman BM, Cira JC, et al: Patient satisfaction measurement strategies: a comparison of phone and mail methods. Jt Comm J Qual Improv 2001, 27:349-361.

28. Perkins JJ, Sanson-Fisher RW: An examination of self- and telephoneadministered modes of administration for the Australian SF-36. J Clin Epidemiol 1998, 51:969-973.

29. de Vries H, Elliott MN, Hepner KA, et al: Equivalence of mail and telephone responses to the CAHPS Hospital Survey. Health Serv Res 2005, 40:2120-2139.

30. McHorney CA, Kosinski M, Ware JE Jr: Comparisons of the costs and quality of norms for the SF-36 health survey collected by mail versus telephone interview: results from a national survey. Med Care 1994, 32:551-567.

31. Gasquet I, Falissard B, Ravaud P: Impact of reminders and method of questionnaire distribution on patient response to mail-back satisfaction survey. J Clin Epidemiol 2001, 54:1174-1180.

32. Hepner KA, Brown JA, Hays RD: Comparison of mail and telephone in assessing patient experiences in receiving care from medical group practices. Eval Health Prof 2005, 28:377-389.

doi:10.1186/1471-230X-12-96

Cite this article as: Azmi et al: Evaluation of patient satisfaction of an outpatient gastroscopy service in an Asian tertiary care hospital. BMC Gastroenterology 2012 12:96.

\section{Submit your next manuscript to BioMed Central and take full advantage of:}

- Convenient online submission

- Thorough peer review

- No space constraints or color figure charges

- Immediate publication on acceptance

- Inclusion in PubMed, CAS, Scopus and Google Scholar

- Research which is freely available for redistribution 